\title{
Gestão eficiente de empresas e seus reflexos positivos na construção civil
}

\author{
Efficient management of companies and their positive effects on civil construction \\ Gestión eficiente de las empresas y sus efectos positivos en la construcción civil
}

\section{Resumo}

Este trabalho tem como objetivo determinar a relação entre capital de giro e níveis de eficiência nos negócios. É importante destacar os efeitos favoráveis das obras de construção civil no crescimento e desenvolvimento econômico e social de uma região, mas também é necessário parar e analisar se a sua execução é acompanhada de critérios de eficiência e produtividade que afetam a redução de custos, por exemplo. É necessário analisar a maneira como esse processo é gerenciado, ainda mais se foram identificadas deficiências técnicas e gerenciais que dificultam a consecução dos objetivos relacionados ao cumprimento de prazos, custos e, em alguns casos, qualidade na execução de obras públicas. Diante desse, identificou-se que a falta de planejamento adequado e a baixa qualidade dos profissionais responsáveis pelo projeto e execução obras, seriam as principais causas, entre outras, dessas deficiências. Nessas circunstâncias, é obrigatório que as empresas melhorem suas capacidades para a concepção, projeto e execução de obras de forma que contribuam para o bem-estar e satisfação das necessidades de seus clientes.

Palavras-chave: Competitividade; Eficiência; Produtividade.

\begin{abstract}
This work aims to determine the relationship between working capital and business efficiency levels. It is important to highlight the favorable effects of civil construction works on the economic and social growth and development of a region, but it is also necessary to stop and analyze whether their execution is accompanied by efficiency and productivity criteria that affect cost reduction, for example. It is necessary to analyze the way this process is managed, especially if technical and managerial deficiencies were identified that hinder the achievement of objectives related to meeting deadlines, costs and, in some cases, quality in the execution of public works. In view of this, it was identified that the lack of adequate planning and the low quality of professionals responsible for the design and execution of works would be the main causes, among others, of these deficiencies. In these circumstances, it is mandatory that companies improve their capabilities for the conception, design and execution of works in a way that contributes to the well-being and satisfaction of their customers' needs.
\end{abstract}

Keywords: Competitiveness; Efficiency; Productivity.

\section{Resumen}

Este trabajo tiene como objetivo determinar la relación entre el capital de trabajo y los niveles de eficiencia empresarial. Es importante destacar los efectos favorables de las obras de construcción civil en el crecimiento y desarrollo económico y social de una región, pero también es necesario detenerse y analizar si su ejecución va acompañada de criterios de eficiencia y productividad que afecten la reducción de costos, por ejemplo. Es necesario analizar la forma en que se gestiona este proceso, especialmente si se identificaron deficiencias técnicas y de gestión que dificultan el logro de objetivos relacionados con el cumplimiento de plazos, costos y, en algunos casos, calidad en la ejecución de obras públicas. Ante ello, se identificó que la falta de una planificación adecuada y la baja calidad de los profesionales responsables del diseño y ejecución de las obras serían las principales causas, entre otras, de estas deficiencias. En estas circunstancias, es obligatorio que las empresas mejoren sus capacidades para la concepción, diseño y ejecución de obras de forma que contribuyan al bienestar y satisfacción de las necesidades de sus clientes.

Palabras clave: Competitividad; Eficacia; Productividad. 


\section{Introdução}

A construção é um participante importante nas economias dos países em desenvolvimento. Nesses países, um déficit habitacional considerável é evidente e é comum que seus governos gerem políticas que incluam alocações orçamentárias diretas ou através de instituições financeiras, que tendem a impulsionar o setor da construção, gerando fontes de emprego e um movimento significativo de matérias-primas (Alves, 2012).

Atualmente, no Brasil, a indústria da construção é um importante gerador de crescimento econômico e contribui consideravelmente para o produto interno bruto (PIB) do país. De 2003 a 2013, foi determinada uma participação média de 8,6\% e, após 2013, a participação do setor de construção atinge uma média de 10,7\% do PIB total. Devido à sua perspectiva de crescimento, a construção ganhou notoriedade do ponto de vista comercial, mas a falta de ferramentas técnicas e econômicas que permitam um gerenciamento organizacional adequado foi evidenciada, tornando necessário gerar estudos setoriais e comerciais que tendem a um gerenciamento eficiente de recursos (Silva, 2017).

Para a maximização dos lucros nas empresas de construção, existem várias estratégias utilizadas por seus gerentes, como, por exemplo, a exploração de economias de escala, onde a administração é orientada para a realização de grandes projetos. Existem também abordagens estratégicas destinadas a reduzir custos e outras, como gerenciamento financeiro ideal de caixa e fluxos de caixa (Alves, 2012).

Toda empresa de construção tenta garantir que os fluxos de caixa sejam adequados para cobrir as obrigações de curto prazo, o que garante o desenvolvimento técnico oportuno das obras, ou seja, sua execução de acordo com o cronograma. Portanto, a disponibilidade de recursos de curto prazo deve ser suficiente para cobrir a demanda por fundos também no curto prazo, que é financeiramente conhecido como "Capital de Giro" (Da Silva; Callado, 2018).

Porém financeiramente qualquer excedente resultante após a cobertura de obrigações de curto prazo deve ser mantida no mínimo, uma vez que existe um custo de capital ou custo da dívida por trás desses fundos e, portanto, o gerente de construção optaria por uma estratégia de redução de capital de giro. Como alerta o autor, gerenciar uma gestão eficiente de recursos, reduzindo o capital de giro a seus níveis mínimos, é uma prática comum; no entanto, o problema está na ausência de estudos que determinem a eficácia dessa medida (Garrison; Brewer 2007).

Este trabalho tem como objetivo determinar a relação entre capital de giro e níveis de eficiência nos negócios. Devido à necessidade de esclarecer a eficácia de certas práticas ou estratégias de negócios, surge a seguinte pergunta de pesquisa: A administração baseada na redução do capital de giro gera níveis aumentados de eficiência nos negócios?

\section{Metodologia}

Trata-se de uma pesquisa de revisão da literatura, de metodologia descritiva, apresentada de modo qualitativo. De acordo com Soares et al., (2014) configura-se como um tipo de revisão da literatura que reúne achados de estudos desenvolvidos mediante diferentes metodologias, permitindo aos revisores sintetizar resultados sem ferir a filiação epistemológica dos estudos empíricos incluídos.

Portanto, um estudo integrativo configura-se como uma espécie de revisão de literatura, que pode coletar resultados de pesquisas desenvolvidas por diferentes métodos, possibilitando assim os revisores sintetizar os resultados, sem comprometer uma conexão epistemológica da pesquisa empírica contida. Para conduzir esse processo de maneira lógica, a revisão integrativa exige que os revisores, analisem e sintetizem os dados originais de maneira sistemática e rigorosa (Souza; Silva; Carvalho, 2016).

O método qualitativo é considerado o trabalho mais adequado para a visão de pessoas e grupos, estando perfeitamente adaptado às características destinadas a responder a questões de personalidade e particularidade, pois é caracterizado pelas ciências sociais que não pode ser quantificado. Portanto, esse método atua sobre o universo de causas, crenças, significados, 
atitudes, ideais e valores que produzem respostas importantes, explicativas e profundas que têm a capacidade de gerar novos relatos não adequados para dados quantitativos (Souza; Silva; Carvalho, 2016).

A coleta de dados foi realizada mediante busca eletrônica, nas bases de dados Scientific Electronic Library Online (SCIELO) e Google Scholar. A temática em questão, foi desenvolvida tendo o enfoque de pesquisa voltado para a questão norteadora.

Para os critérios de inclusão foram utilizados artigos completos em língua portuguesa, monografias, livros e dissertações disponíveis eletronicamente e que obedeçam à temática supracitada. Referente aos critérios de exclusão estão: relatos de experiência, e pesquisas duplicadas.

Assim, para análise de conteúdo e classificação dos artigos foram seguidos os seguintes passos:

a) Pré-análise: leitura flutuante do material coletado; constituição do corpus da pesquisa;

b) Exploração do material: recorte em unidades de registro de contexto; codificação e classificação segundo categorias empíricas e teóricas;

c) Tratamento dos dados e interpretação: análise final dos dados obtidos. Não sendo necessária a aprovação por um Comitê de Ética em Pesquisa por se tratar de uma pesquisa bibliográfica.

\section{Resultados e Discussão}

\subsection{Empresas de construção civil}

Pode-se considerar que as empresas de construção civil têm ganhando um imenso espaço no desenvolvimento brasileiro em comparação com décadas e períodos históricos anteriores, considerando o desenvolvimento econômico e social ao qual o Brasil está vivenciando. Com as melhorias realizadas para com as empresas do setor de construção civil, mudanças e modificações tanto no desenvolvimento de novos projetos como qualidade dos mesmos e nas condições de sustentabilidade que certamente vem preocupando e ganhando espaço nas referidas empresas (Dutra, 2013).

Quando nos referimos ao desenvolvimento da construção civil também há de se considerar que algumas regiões brasileiras estão devidamente saturadas ao passo que outras regiões são totalmente carentes desse tipo de desenvolvimento. O que vem a facilitar as empresas de construção civil em regiões como o Centro-Oeste hoje, apesar dos programas de qualidade terem impulsionado o mercado a exigir um trabalhador com um novo perfil de treinamento e qualificação, as exigências para este novo perfil profissional ainda não regulam as ações de valorização dos recursos humanos de muitas empresas (Dutra, 2013).

As empresas de construção civil são as que mais se desenvolvem nos últimos anos, isso ocorre devido aos incentivos ofertados pelo governo e pelo acelerado crescimento de infra-estrutura dentro do país. Na mesma proporção em que se destacam pela quantidade de oportunidades que estas empresas oferecem, também estão no topo das taxas de rotatividade de pessoal em relação às demais organizações (Fortes, 2011).

No que se refere à seleção de mão de obra, treinamento e comprometimento com a qualidade dos serviços, o setor de recursos humanos da construção civil não apresentou avanços. O processo de seleção dos operários ainda ocorre sem um critério que defina a função que o mesmo irá desempenhar no cargo. Este fato, frequente no setor, subestima a necessidade de uma preparação adequada dos recursos humanos (Bertizzolo; Matos, 2019).

Os índices de demissões de trabalhadores pela própria empresa chegam a 86,2\%. Estes dados foram divulgados no ano de 2011 pelo Dieese (Departamento Intersindical de Estatística e Estudos Socioeconômicos), com base em números de 2009 da Relação Anual de Informações Sociais (RAIS) do Ministério do Trabalho e Emprego (MTE). Este valor pode ainda aumentar se levar em consideração os fatores alheios à vontade das empresas, como aposentadoria, morte ou demissão voluntária: 108,2\%. Onde, neste caso, para cada vínculo do estoque médio do setor, em cada ano, existiram um ou mais vínculos desligados (Brandalise, 2017). 
Desta forma, o que se verifica é que muitas empresas da construção civil desconhecem as percepções e intenções dos trabalhadores com relação às atividades que desempenham e a própria profissão (Lima; Albano, 2002).

As empresas de construção civil são consideradas como "molas" propulsoras da economia brasileira, ou seja, são de grande importância para o desenvolvimento tanto dos indivíduos como para a população de um modo geral. Além das referidas empresas envolverem os setores da indústria específica da construção civil, envolvem também demais ciclos de desenvolvimento tais como produtores de máquinas e equipamentos e empresas responsáveis por contratação de mão-de-obra especializada ou operacional (Costa, 2011).

Ao se considerar o Brasil um país de economia emergente pode-se considerar ao mesmo tempo em que as indústrias e empresas do ramo de construção civil são prioridades no desenvolvimento do país e da economia de uma forma geral. E ainda pode-se considerar que esse tipo de empreendimento tem como fonte de profissionais a classe média baixa da economia brasileira, em especial os indivíduos do sexo masculino e com baixa instrução de escolaridade ou sem nenhuma instrução e claro, com força física e desprendimento familiar, histórico e regional (devido às mudanças e transferências de cidades, estados ou países).

Além das inovações tecnológicas e das melhores condições de desenvolvimento de trabalho e das atividades dos profissionais, quanto as empresas de construção civil pode-se considerar que dos anos o mercado brasileiro ficou mais aberto para as demais empresas estrangeiras, o que vem a facilitar o desenvolvimento de obras e grandes empreendimentos, sem deixar a participação das empresas brasileiras, são os conhecidos e falados consórcios entre as mesmas. Quando nos referimos ao desenvolvimento da construção civil também há de se considerar que algumas regiões brasileiras estão devidamente saturadas ao passo que outras regiões são totalmente carentes desse tipo de desenvolvimento. O que vem a facilitar as empresas de construção civil em regiões como o Centro-Oeste, Norte e Nordeste (Nakamura, 2014).

De acordo com Drehmer (2006), esta baixa qualificação do trabalhador da construção civil tem forte influência sobre a baixa produtividade, além de estar relacionada a outros problemas, como a resistência deles às inovações tecnológicas - o método tradicional de construir persiste, sendo incorporado e difundido pelos próprios trabalhadores - e à própria capacitação profissional.

A autora menciona ainda que a política de se empreitar adotada pelas empresas é que colabora para um processo de recrutamento de trabalhadores pouco qualificados e ainda, para a intensa geração dos contratos informais.

O mercado de trabalho oferece, hoje, poucas opções às pessoas sem qualificação. Neste cenário, a construção civil torna-se atrativa para aqueles sem uma profissão definida, mesmo que as condições do trabalho apresentem-se como inseguras e que o emprego em si, como instável. Dessa forma, o setor é caracterizado por uma elevada absorção de mão de obra sem especialização adequada para o trabalho (Costa, 2011).

Com as melhorias realizadas para com as empresas do setor de construção civil, mudanças e modificações tanto no desenvolvimento de novos projetos como qualidade dos mesmos e nas condições de sustentabilidade que certamente vem preocupando e ganhando espaço nas referidas empresas. Ao mesmo tempo em que as empresas de construção civil ficam obrigadas a respeitar novos valores em seu desenvolvimento e aprimoramento das tecnologias em vigor, os profissionais que nelas trabalham também se encontram no momento de realizar novos treinamentos e desenvolver outras habilidades não exigidas até então (Santos, 2017).

Nesse sentido Piori Junior (2007, p. 03) nos dizem que:

As inúmeras mudanças exigidas das habilidades do trabalhador, neste final de século, concomitantemente com a evolução da tecnologia, fazem com que os mesmos sejam facilmente descartáveis no mercado de trabalho. Isto, devido ao fato de que este trabalhador, de baixa escolaridade, não reúne condições e muito menos tem chances para aprender sozinho uma profissão, quanto mais uma qualificação ou mesmo uma re-qualificação profissional. Portanto, com a vinda da era digital e da tecnologia percebe- 
se que também se fazem necessárias mudanças nas vidas dos trabalhadores (profissionais) quanto ao desempenho de suas atividades. Então um carpinteiro ou um pedreiro na era das tecnologias pode muito bem conhecer e desenvolver suas atividades de uma forma menos arcaica e mais produtiva para a empresa de construção civil.

Então o desenvolvimento amazônico baseia-se em projetos de grande escala e dimensão nacional e/ou internacional. E diante dessa realidade pode-se perceber que as zonas de desenvolvimento econômico brasileiro estão se transferindo das regiões sul e sudeste e se mobilizando para o centro-oeste, norte e nordeste, os focos de atuação das empresas de construção civil (Drehmer et al., 2006).

\subsection{Eficiência no desempenho das obras}

Considerando os enormes recursos econômicos que estão sendo alocados em projetos de investimento em obras, a análise da eficiência em sua execução torna-se um processo muito relevante devido à importância que as obras representam no crescimento e desenvolvimento econômico de uma região e no impacto no bem-estar de sua população, também, porque esse aumento no investimento em obras - sem precedentes nos últimos anos - também é acompanhado por um aumento significativo no custo médio de sua execução (De Oliveira; De Souza; 2021).

Diante desse cenário e como resultado das auditorias realizadas em obras, as empresas identificaram que os problemas mais frequentes estão basicamente relacionados a aumentos injustificados nos prazos de execução e nos orçamentos de trabalho, seja por mau planejamento durante a fase de estudo e preparação do arquivo técnico ou gerenciamento inadequado durante a fase de execução. Esses problemas definitivamente causam desequilíbrios que afetam a viabilidade dos investimentos, o que se traduz não apenas em desperdício e desperdício de recursos, causando maiores despesas e alocações de orçamento, aumentando significativamente o custo de execução (Gutheil, 2004).

Entre os principais problemas constantemente identificados, podemos citar:

- Ineficiências nos estudos de engenharia realizados na fase de projeto, devido a informações deficientes ou nulas relacionadas ao projeto, devido à não observância dos regulamentos e normas técnicas aplicáveis à natureza do projeto ou devido à ignorância das condições climáticas ou geomorfológicas da área onde o trabalho é realizado;

- Orçamento inadequado de obras que não permita conhecer em detalhes e precisão as quantidades e características dos insumos a serem utilizados, bem como seu preço de mercado, muitas vezes supervalorizando os custos das obras;

- Modificações nos projetos de engenharia e nos orçamentos aprovados inicialmente, incorporando trabalhos adicionais quando o trabalho já estiver em andamento;

- Seleção de construtoras que não possuem capacidade técnica ou suporte financeiro para cumprir as obrigações contratuais e a finalidade do contrato, devido a fatores inadequados de avaliação aplicados no processo de seleção;

- Aumentos nos tempos de execução devido a atrasos injustificados da empresa contratada, sem que sejam aplicadas as penalidades por atraso na execução, nem as ações corretivas necessárias;

- Supervisão inadequada durante a execução da obra, seja pelo mau desempenho das funções dos profissionais designados para ela, seja pelo não cumprimento das consultorias contratadas para esse fim, que muitas vezes levam a deficiências de construção;

- Procedimentos administrativos e legais relacionados a licenças, aprovações, limpeza de terras e autorizações perante outras entidades do Estado.

Quando as obras são executadas diretamente pela administração da entidade, ou seja, quando as empresas assumem diretamente o papel de construtor, os problemas detectados também são associados aos detalhados acima - com exceção dos relacionados à contratação de empresas - elas não possuem capacidade administrativa suficiente para realizar a construção e / ou 
execução de uma obra, pois foram identificados um gerenciamento ineficiente dos insumos e recursos destinados a elas, organização e direção inadequadas, e, finalmente, processos de controle escassos ou quase nulos (Sousa; Cândido; Barros, 2018).

Da mesma forma, o dano econômico de uma obra ineficientemente construída acaba sendo alto, porque uma infraestrutura mal construída aumenta os custos de manutenção. A longo prazo, as entidades regionais incorrerão em despesas contínuas para manter o bom funcionamento do mesmo. Portanto, a falta de eficiência nos gastos traduzida em infraestruturas supervalorizadas, paralisadas, inacabadas e / ou abandonadas tirar vantagens competitivas de toda atividade econômica e, portanto, reduz a competitividade para as regiões. Neste ponto e diante da análise da falta de eficiência (Mubarak, 2010).

Embora o planejamento seja uma função de todo o processo de gerenciamento - o conceitualizou com termos diferentes

como administração, direção e / ou gerenciamento, sem apreciar diferenças significativas em sua essência e conteúdo - é necessário destacar a importância do planejamento na execução das obras, pois isso é complexo devido à grande variedade de considerações e fatores que devem ser levados em consideração, e também porque, no processo de gestão, é a função norteadora e a que determina os objetivos (Sousa; Cândido; Barros, 2018).

O planejamento, portanto, torna-se um processo fundamental, que se estende por todo o ciclo de vida de uma obra, desde sua concepção e design até sua execução e manutenção. Em princípio, os trabalhos devem ser priorizados com rigor, utilizando critérios estritos de competitividade, coesão territorial e rentabilidade social e econômica. É necessário se concentrar mais em análises e decisões, para alcançar com mais eficiência os objetivos que importam mais coletivamente (Sousa; Cândido; Barros, 2018).

Diante desses fatos, é necessário avaliar a importância de um planejamento adequado na concepção e execução de projetos de obras. Existem muitos poucos ambientes, como a execução de uma obra, em que é necessário planejar várias frentes de atividades simultaneamente, envolvendo o manuseio de uma quantidade significativa de informações, além de que as obras, por sua própria definição, são limitadas em tempo, para que o planejamento seja normalmente realizado sob fortes restrições de tempo.

\subsection{Falta de habilidades e competências profissionais}

Várias atividades são realizadas no processo de execução de uma obra (projeto e construção), e a natureza de cada uma delas é bastante complexa em si mesma, o que exige - além de o conhecimento técnico e de engenharia com o qual se deve ter capacidades que permitam uma gestão adequada dos recursos, determinando a razoabilidade, prudência e eficiência nas despesas durante a execução das obras. Agora, o que acontece com as capacidades e competências necessárias para desenvolver esse processo, uma vez que um fenômeno geral ocorre em todos os governos regionais, e é a alta rotatividade de profissionais envolvidos na execução das obras, uma vez que estão sujeitos a constantes mudanças toda vez que uma nova administração assume o gerenciamento dessas entidades (Kala et al, 2012).

É muito comum observar que os governantes em serviço permitem o acesso do pessoal sem um processo de seleção adequado - onde o mérito e a experiência são privilegiados - o que gera uma ineficiência contínua na execução das obras. As administrações não levam em conta o acúmulo e o uso da experiência, não têm consciência de que cada trabalho realizado gera um espaço de aprendizado, bem como uma oportunidade para desenvolver novas capacidades (Bressiani; Roman, 2017).

Nesse cenário, a transmissão e o acúmulo de conhecimento são muito complexos, senão impossíveis, porque, com essas constantes mudanças na equipe profissional, as habilidades e conhecimentos adquiridos não podem ser revertidos na execução de novas obras própria natureza e complexidade de alguns deles - cada trabalho é único - e o individualismo de alguns profissionais. O crescimento econômico não é apenas resultado de investimentos, mas também de capital humano, pois quanto maior o conhecimento de uma determinada área, maior o nível de eficiência no trabalho realizado e maior a produtividade (Bressiani; Roman, 2017). 
Ademais, as entidades devem capturar e acumular o conhecimento dos profissionais e transformá-lo para que seja útil para futuros projetos e execuções de obras públicas, ou seja, eles devem aprender e começar a gerenciar o conhecimento. Da mesma forma, nota-se que a falta de habilidades dos profissionais também é acompanhada pela falta de capacidades institucionais ou organizacionais, uma vez que não possuem todos os elementos necessários para permitir uma gestão adequada de obras públicas, como estilos de gestão e liderança, os procedimentos adequados, a estrutura organizacional, entre outros (Moreira; Bernardes, 2001).

\section{Considerações Finais}

A partir dos resultados anteriores, podem ser obtidas as seguintes conclusões:

Grandes empresas de construção alcançam um alto nível de eficiência no desenvolvimento de suas atividades, observando estratégias diferenciadas que respondem a diferentes políticas de produção e vendas.

O desenvolvimento de um modelo de "benchmarking" de duas fases (sem e com "folgas") facilita a implementação de políticas de melhoria nas empresas, permitindo que as ações mais urgentes sejam realizadas no curto prazo e deixando as mudanças mais agressivas no longo prazo.

A consideração da orientação "entrada" e "saída" permite analisar o desempenho da empresa a partir de duas abordagens diferenciadas: minimização do consumo de recursos e maximização das saídas geradas. Dessa maneira, informações úteis são fornecidas a um grupo mais diversificado de usuários

\section{Referências}

Adami, R. L. (2009). O Absenteísmo e a Rotatividade de Pessoal em Empresas de Construção Civil: O Estudo de Caso da Mendes Sibara Engenharia de ItajaíSC. Trabalho de Conclusão de Curso do Instituto Cenecista Fayal de Ensino Superior. Itajaí.

ALVES, A. (2012). Organização do canteiro de obras: um estudo aplicativo na Construção do Centro de Convenções de João Pessoa-PB. João Pessoa, UFPB. Amaral, T. G. D. (1999). Elaboração e aplicação de um programa de treinamento para trabalhadores da indústria da construção civil.

Bergamini, C. W. (2000). Motivação Nas Organizações . Editora Atlas SA.

Bergamini, C. W. (2000). Psicologia aplicada à administração de empresas: psicologia do comportamento organizacional . Editora Atlas SA.

Bernardes, M. M. (2001). Desenvolvimento de um modelo de planejamento e controle da produção para micro e pequenas empresas de construção.

Bertizzolo, M., \& Mattos, T. C. D. (2019). Gestão temporal na construção civil. Engenharia Civil-Pedra Branca.

BRANDALISE, D. (2017). A importância do gerenciamento do tempo em projetos de construção civil. Trabalho de Conclusão de Curso. Pós-Graduação lato sensu, 57.

Bressiani, L., \& Roman, H. R. (2017). A utilização da Andragogia em cursos de capacitação na construção civil. Gestão \& Produção, $24,745-762$.

Busnardo, E. A. (2005). Autogestão em construção: o caso de uma cooperativa da construção civil do Rio de Janeiro (Doctoral dissertation).

Chiavenato, I. (1997). Administração de Recursos Humanos: fundamentos Básicos. São Paulo. Atlas. 1999. Recursos Humanos, $2001-2011$.

Chiavenato, I. (2002). Teoria geral da administração. Elsevier Brasil.

Chiavenato, I. (2003). Administração de recursos humanos: fundamentos básicos. Atlas.

Idalberto, C. (2004). Recursos humanos, o capital humano das organizações. Atlas, São Paulo, 577.

Chiavenato, I. (2009). Desempenho humano nas empresas: como desenhar cargos e avaliar o desempenho para alcançar resultados. Manole.

Costa, L. R. (2011). Subcontratação e informalidade na construção civil, no Brasil e na França. Caderno CRH, 24, $413-434$.

Silva, A. R., \& Callado, A. L. C. (2018). Aderência de indicadores de desempenho associados às perspectivas do Balanced Scorecard no setor de construção civil do município de João Pessoa (PB). REUNIR Revista de Administração Contabilidade e Sustentabilidade, 8(2), $23-34$.

Dall'inha, G. R. (2005). A influência das práticas e das políticas de recursos humanos sobre o absenteísmo e a rotatividade: um estudo de caso.

de Oliveira, V. P., \& de Souza, L. F. A. (2021). Análise da Viabilidade Técnica do Uso de Contêineres Marítimos na Construção Civil para Habitações Sociais. Epitaya E-books, 1(6), 134-163. 
Research, Society and Development, v. 10, n. 14, e234101421893, 2021

(CC BY 4.0) | ISSN 2525-3409 | DOI: http://dx.doi.org/10.33448/rsd-v10i14.21893

Dowbor, L., \& Alexandre, I. M. (2002). O que acontece com o trabalho? (Vol. 10). Editora Senac São Paulo.

Drehmer, C. P. (2006). Motivação no ramo da construção civil: um estudo de caso na empresa Steffen \& Drehmer Ltda.

Dutra, J. S. (2002). Gestão de pessoas: modelo, processos, tendências e perspectivas. Atlas.

Fortes, F. S. D. (2011). Influência do gerenciamento de riscos no processo decisório: análise de casos (Doctoral dissertation, Universidade de São Paulo).

Gentil, M. S. (2017). Implantação da produção enxuta: análise de modelos e práticas na Indústria Automobilística e na Construção Civil.

Gutheil, K. O. (2004). Desenvolvimento de sistemas de planejamento e controle da produção em micro-empresas de construção civil, com foco no planejamento integrado de várias obras.

Honorio, D. E. (2002). A qualidade de vida do operário da construção civil e sua importância na qualidade e produtividade em obras.

Kala, T., Mouflard, C., \& Seppänen, O. (2012, December). Production control using location-based management system on a hospital construction project. In Proceedings of the 20th Annual Conference of the International Group for Lean Construction. San Diego: IGLC.

Lima, S. M. B., \& Albano, A. G. B. (2002). Um estudo sobre clima e cultura organizacional na concepção de diferentes autores. Rev. CCEI-URCAMP, 6(10), 33-40.

Lima, S. M. B., \& Albano, A. G. B. (2002). Rev. CCEI-URCAMP, v. 6, n. 10.

Marcon, S. R. A. (1998). Fatores que influenciam na permanência das pessoas na empresa: dois estudos de casos: uma empresa moveleira e uma empresa metalúrgica.

Nakamura, J. (2014). Como fazer o gerenciamento de obras. Revista Online AU PINE. Ed, 245.

Priori Junior, L. (2007). Ações para a Melhoria da Satisfação do Trabalhador em Canteiros de Obras.

Santos, M. F. D. (2017). Análise do nível de motivação entre profissionais autônomos da construção civil.

Silva, A. R. D. (2017). Relações entre fatores contingenciais de empresas do setor da construção civil e a importância atribuída a indicadores de desempenho.

Solomon, J. A. (2004). Application of the principle of lean production to construction (Doctoral dissertation, University of Cincinnati). 